\title{
Short Communication: Erythrocytes and leukocytes profiles of bottlenose dolphins (Tursiops aduncus) at conservation site
}

\author{
ARYANI SISMIN SATYANINGTIJAS ${ }^{1, \vartheta}$, AGUSTIN INDRAWATI ${ }^{2}$, RIZKA F. SYARAFINA ${ }^{1}$, TALITA F. MILANI ${ }^{1}$, \\ M. SURYAPUTRA ${ }^{1}$, AINUL KHADIJA SALEEMA ${ }^{1}$, DESRAYNI HANADHITA ${ }^{1}$ \\ ${ }^{1}$ Departement of Anatomy, Physiology dan Pharmacology, Faculty of Veterinary Medicine, Institut Pertanian Bogor. Jl. Agatis, Kampus IPB Darmaga, \\ Bogor 16680, West Java, Indonesia. Tel./fax.: +62-251-8629469, ^email: niekesis@ yahoo.co.id \\ ${ }^{2}$ Department of Animal Diseases Science and Veterinary Public Health, Faculty of Veterinary Medicine, Institut Pertanian Bogor. Jl. Agatis, Kampus IPB \\ Darmaga, Bogor 16680, West Java, Indonesia
}

Manuscript received: 7 February 2020. Revision accepted: 28 June 2020.

\begin{abstract}
Satyaningtijas AS, Indrawati A, Syarafina RF, Milani TF, Saleema AK. 2020. Short Communication: Erythrocytes and leukocytes profiles of bottlenose dolphins (Tursiops aduncus) at conservation site. Biodiversitas 21: 3359-3363. Health monitoring of dolphins to ensure optimal welfare in human care is important. This study measured erythrocytes and leukocytes in seven bottlenose dolphins (Tursiops aduncus) as a parameter to assess physiological status in PT. Wersut Seguni Indonesia (WSI) Marine Mammals Conservation. Blood was sampled through the superficial veins of each tail fin for examination of erythrocytes and leukocytes using hemocytometer method. Differential leukocytes were observed using thin blood smears stained by Giemza. The purpose of this study to collect hematological value of captive bottlenose dolphins. The results showed values of erythrocytes was $(5.14 \pm 0.56) \times 10^{6} / \mathrm{mm}^{3}$, $(13.86 \pm 1.68) \mathrm{gr} / \mathrm{dl}$ for hemoglobin, and $(44.29 \pm 2.69) \%$ for hematocrit. The value for leukocytes were $(4.2 \pm 0,82) \times 10^{3} / \mathrm{mm}^{3}, 63.14 \pm$ $9.77 \%$ for lymphocytes, $3.57 \pm 1.72 \%$ for monocytes, $31.57 \pm 8.43 \%$ for neutrophils, $1.29 \pm 1.60 \%$ for eosinophils and $0.14 \pm 0.38 \%$ for basophils. The average of the seven bottlenose dolphins Neutrophil to Lymphocyte ratio (N/L) was 0.53 .
\end{abstract}

Keywords: Bottlenose dolphin, erythrocytes, leukocyte, stress index

\section{INTRODUCTION}

Dolphins in the order cetaceans are marine mammal with high intelligence, docile nature, patient, tame quickly and easy to train (Gauckler 1982). As a result of their nature, many dolphins remain in human care for conservation and education. In Indonesia, dolphins are protected under UU No.5 of the year 1990 on Conservation of Natural Resources and Ecosystems followed by the affirmation of the status of dolphins as animals that are protected by the state annexed to the attachment of Government Regulation No. 7 of the year 1999 on Preservation of Plants and Animals. The status of dolphins as animals that are protected by the state makes the healthcare of the dolphins became a thing that must be considered. The monitoring of the health of captive dolphins can be done by looking at the interpretation of erythrocytes, leukocytes and its differentiation in common bottlenose dolphin (Tursiops aduncus) that plays a role in physiological and immune mechanism. In addition, the psychological condition of the dolphins can also affect their health. Stress index of living beings can be determined by conduct the examination of the ratio of neutrophils to lymphocytes (N/L) (Davis et al. 2008; Hickman 2017). The purpose of this research is to calculate the number of erythrocytes, leukocytes and differential leukocytes on common captive bottlenose dolphin as a parameter which can be used to help further diagnosis and determine stress index of the dolphins living in captivity and environmental conditions that supports the health of the dolphins.

\section{MATERIALS AND METHODS}

This research was conducted in the Marine Mammal Conservation Site at Cahaya Beach, Sendang Sikucing, Kendal, owned by PT Wersut Seguni Indonesia (WSI) and Pawiyatan Luhur Laboratory at Bendandhuwur, Semarang, Central Java. A total of seven bottlenose dolphins were included in the study. This research method began by taking blood from the examined animal under manual restraint from the periarterial venous rete on the dorsal fluke using a $21 \mathrm{G}$ needle and a $5 \mathrm{ml}$ syringe. The blood was stored in a heparinized test tube and transported to the private laboratory which is usually used as a reference laboratory for dolphin blood tests in that region. Blood examination parameters include the total erythrocytes count, hemoglobin concentration $(\mathrm{Hb})$, hematocrit (HCT), mean corpuscular volume (MCV), mean corpuscular hemoglobin $(\mathrm{MCH})$, mean corpuscular hemoglobin concentration (MCHC), total leukocyte count, and leukocyte differentiation. Blood smear preparations were also made to observe the morphology of blood cells. N/L ratio was calculated based on the value of leukocytes differential obtained. 


\section{RESULTS AND DISCUSSION}

Hematology profile obtained was compared with the hematology value of the free-range Pacific bottlenose dolphin (Fair et al. 2006) (Table 1). Total erythrocyte count has a higher value than free-range dolphins. $\mathrm{Hb}$ and $\mathrm{HCT}$ are still in the normal interval. However, the $\mathrm{MCV}, \mathrm{MCH}$, and $\mathrm{MCHC}$ levels are lower than free-range dolphins.

Erythrocytes or red blood cells (RBC) are cells that take the most portion of the blood. Erythrocytes contain hemoglobin molecules that function to carry oxygen (Ciesla 2012). Tests related to RBC that are often performed to analyze the incidence of anemia are HCT, $\mathrm{MCV}, \mathrm{MCH}$, and MCHC. HCT is a test to estimate red cell volume and blood's oxygen-carrying capacity. MCV is used to estimate the size of the RBC. MCH calculation is used to calculate the amount of $\mathrm{Hb}$ per $\mathrm{RBC}$. $\mathrm{MCHC}$ is used to measure the amount of $\mathrm{Hb}$ per unit volume (Sarma 1990).

The total erythrocyte values of captive bottlenose dolphins are higher than free-range bottlenose dolphin, but not accompanied by high HCT values. Thus, it indicates that physiologically, captive bottlenose dolphin does have a higher total RBC. HCT fluctuations are common in diving mammal due to blood storage and releasement in the spleen (Thornton et al. 2001; Ilardo et al. 2018). The blood release from the spleen helps the distribution of sufficient oxygen while diving. However, this condition is not applied to bottlenose dolphins because they do not have the capacity to store blood in the spleen (Udroiu 2017). Therefore, there is no difference in HCT between captive and free-range bottlenose dolphin. Although it has a high value, it seems that the RBC of captive bottlenose dolphin does not have a good affinity for $\mathrm{Hb}$. Lower MCV indicates that captive bottlenose dolphin has a smaller RBC size compared to free-range bottlenose dolphin. The small size of the RBC makes the binding capacity to the $\mathrm{Hb}$ molecule also smaller which is characterized by lower MCH and MCHC values. Hematologic observations on harbor seals pups in captivity show that the area and depth of pools in captivity affect the value of $\mathrm{MCV}, \mathrm{MCH}$, and $\mathrm{MCHC}$ (Thomas and Ono 2015). This is related to shallow depth and shorter dive duration in captivity. However, the low oxygen capacity does not affect the difference of diving ability in the wild, so that the release of marine mammals from captivity is still possible.

Morphological observations of leukocytes or white blood cells (WBC) were made from blood smear preparations. Population and morphology of the WBC of bottlenose dolphins are generally the same as mammals in general, as stated by (Shirai and Sakai 1997; Nouri-Shirazi et al. 2017). WBC populations that are identified on blood smear preparations, consisting of neutrophils, lymphocytes, eosinophils, basophils, and monocytes (Figure 1).

Table 1 showed the total number of leukocytes of captive bottlenose dolphins from our study was lower compared to total number of leukocytes that Patricia et al. reported in 2006. The total number of leukocytes is affected by one or several types of leukocytes (Frandson et al. 2003). Fluctuations in the number of leukocytes can occur in certain conditions, such as stress, nutrition, age, illness, and others. The abnormal number of leukocytes had an important clinical meaning for the evaluation of a disease process (Bacha and Bacha 2000). The abnormal number of leukocytes includes leukopenia and leukocytosis. Leukopenia is a state of white blood cell count is lower than normal (Lonsdale 1995). Leukopenia can be caused by several factors such as bone marrow depression in aplastic anemia case, myelofibrosis, osteoporosis, bacterial infection (Thypus abdominalis, Parathypus, Brucellosis), cytostatic drugs (myleran, mercaptopurine, etc.), and irradiation. Leukocytosis is the increase in the number of leukocytes in circulation. Leukocytosis is a normal response to infection or inflammatory. This situation can be found after emotional disturbances, anesthesia or exercise, and during pregnancy (Corwin 2009). The number of the WBC populations of bottlenose dolphins from this study, successively from the most to the least, were neutrophils, lymphocytes, monocytes, eosinophils, and basophils. In general, WBC population values in wild and captive dolphin bottlenose are neutrophil, eosinophil, lymphocyte, monocyte, and basophil, respectively (Fair et al. 2006; Noda et al. 2007).

Neutrophils the major component of the total number of leukocytes (Frandson et al. 2003). Neutrophils are the first line of cell defense of microorganism invasion by phagocytosis mechanisms. Neutrophil has a very active metabolism and able to do both aerobic and anaerobic glycolysis. The neutrophil ability to live in an anaerobic environment is very favorable, because it can kill bacteria and help clean up debris on the necrotic tissue (Stockham and Scott 2008). Neutrophil count found on the research has shown the same range as reported by Fair et al. (2006). The average number of neutrophil cells in the bottlenose dolphins' blood was $31.6 \%$. The number of neutrophils in the blood is influenced by the presence of infection, inflammation, or stress. Inflammation or infection will stimulate the excess of neutrophils to destroy foreign substances that enter the body. Neutrophil will get the sign from the exact cell or bacterial toxin. In stress conditions, the number of cortisol can affect the neutrophils excess from bone marrow, thus increasing the number of neutrophils (Frandson et al. 2003; Stockham and Scott 2008).

The average number of bottlenose dolphin's eosinophil cells in this study was $1.29 \%$. Table 1 has shown the number of eosinophils in the seven blood samples was less than the range of the number of eosinophils in the blood reported by Fair et al. (2006), namely 26-57\%. Eosinophils play an active role in managing acute allergic and inflammatory processes, organize a parasitic infestation and phagocytes bacteria, antigen-antibody complexes, mycoplasma, and yeast (Bacha and Bacha 2000). Glucocorticoid may affect the number of eosinophils by causing a decrease in the number of blood eosinophils quickly, causes eosinopenia (Reidarson and McBain 1999; Noda et al. 2007). 
Table 1. Hematology values of captive bottlenose dolphins (Tursiops aduncus) in PT. Wersut Seguni, Indonesia

\begin{tabular}{llll}
\hline Hematology & Units & Mean \pm SD & Range* $^{*}$ \\
\hline Erythrocyte & $10^{6} / \mathrm{mm}^{3}$ & $5.14 \pm 0.56$ & $2.3-4.1$ \\
Hemoglobin & $\mathrm{g} / \mathrm{dl}$ & $13.86 \pm 1.68$ & $10.8-15.6$ \\
Hematocrit & $\%$ & $44.29 \pm 2.69$ & $29-47$ \\
Mean Corpuscular Volume (MCV) & $\mathrm{Fl}$ & $86.57 \pm 5.91$ & $97-149$ \\
Mean Corpuscular Hemoglobin (MCH) & $\mathrm{pg}$ & $26.94 \pm 1.23$ & $35-48$ \\
Mean Corpuscular Hemoglobin Concentration (MCHC) & $\mathrm{g} / \mathrm{dl}$ & $31.20 \pm 2.03$ & $32-37$ \\
Leukocyte & $\mathbf{1 0} / \mathbf{m m}^{\mathbf{3}}$ & $4.23 \pm 0.82$ & $7.0-19.1$ \\
Neutrophil & $\%$ of WBC & $31.57 \pm 8.43$ & $12-62$ \\
Eosinophil & $\%$ of WBC & $1.29 \pm 1.60$ & $26-57$ \\
Basophil & $\%$ of WBC & $0.14 \pm 0.38$ & $0-3$ \\
Lymphocyte & $\%$ of WBC & $63.14 \pm 9.77$ & $3-58$ \\
Monocyte & $\%$ of WBC & $3.57 \pm 1.72$ & $0-4$ \\
Neutrophil/lymphocyte (N/L) ratio & & 0.53 & $1.57-4$ \\
\hline
\end{tabular}

Note: Range* : the ranges of total number of the free-range Pacific bottlenose dolphin (Tursiops truncatus) reported by Fair et al. (2006). SD : Standard of Deviation

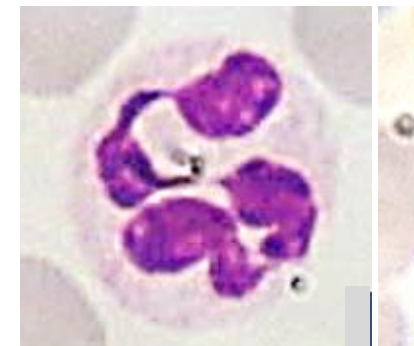

A

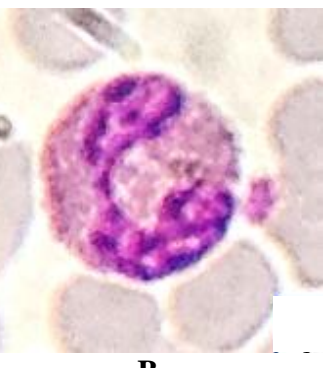

B

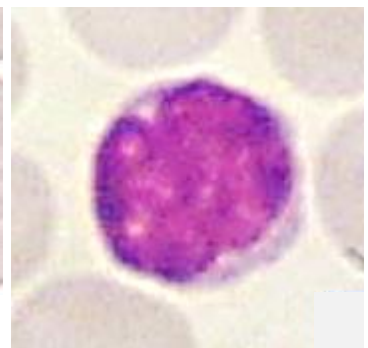

C

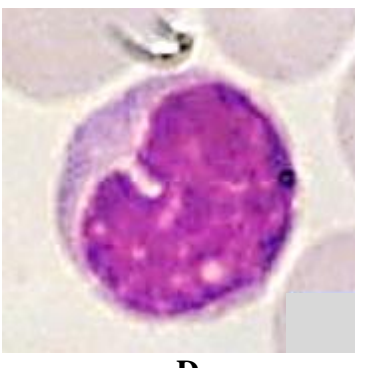

D

Figure 1. Neutrophil (A), eosinophil (B), lymphocyte (C). and monocyte (D) of captive bottlenose dolphins (Tursiops aduncus) from PT Wersut Seguni Indonesia

Lymphocytes are the type of leukocytes that respond to antigen by forming antibodies in circulation and developing immune-mediated cells ( Frandson et al. 2003). According to the research, the numbers of lymphocytes in five of seven blood samples were higher than the range of lymphocytes number reported by Fair et al. (2006). The average number of lymphocytes in this study was $63.1 \%$. The increased number of lymphocytes occurs when antigen enters the body, thus the body produces antibodies ( Frandson et al. 2003). An increase in lymphocyte counts in immunosuppressed conditions can also occur in the incidence of metabolic diseases that follow chronic glucocorticoid secretion (Aranda et al. 2017). The decreased number of lymphocytes occurs when immunosuppression condition or the obstruction in lymphoid tissue as a result of certain factors or if the animal is under a stress condition. Cortisol levels in the blood increase under a stress condition. Cortisol causes lymphopenia by reducing mitosis activity or the formation of lymphocytes. Cortisol also affects the decrease of lymphocyte numbers in circulation caused by lymphocytes redistribution to the bone marrow or other parts (Davis et al. 2008).

The average number of bottlenose dolphins' basophils cells in this study was $0.1 \%$. Table 2 has shown the number of basophils in blood samples equal with the range of basophils number in dolphins blood reported by Patricia et al. (2006) namely 0-3\%. Basophils were only observed in a single sample. The absence of basophils does not mean that animals do not have allergies or inflammation, Basophils are involved in the inflammatory process, therefore there is a delicate balance between basophils and eosinophils in initiating and controlling the inflammation ( Frandson et al. 2003). Phagocytes by basophils are limited, so that basophils are less common. Basophils have a major function in generating a hypersensitive reaction to the secretion of vasoactive mediators. These cells release mediators of inflammation and allergies (Harvey et al. 2012).

The number of monocytes in blood samples equal with the number of monocytes reported by Fair et al. (2006) although on three blood samples found the number of monocytes that exceed the range. Monocytes are not associated with acute inflammation and only remain in circulation for a few days. Monocytes react with lymphocytes in tissue and have an important role in immune-competent cell introduction and interaction to antigen. Monocytes also give pathogen pieces to the $\mathrm{T}$ cell so the pathogen can be recognized and the antibody can be developed (Stockham and Scott 2008; Harvey et al. 2012).

The ratio of the number of neutrophils to lymphocytes was compared to provide a stress indicator for bottlenose 
dolphins. Stress is the body's response to a particular threat in the form of adjustments to these conditions (von Borell 2001). Stress caused by trauma, infection, inflammation, or the destruction of tissue will trigger the nerves impulses to hypothalamus. Chronic stress conditions in vertebrates in general, will cause decrease of lymphocytes number and increase of neutrophils number compared to normal conditions (Davis et al. 2008). In pacific bottlenose dolphin, the condition of transportation stress causes a significant decrease in the number of lymphocytes, eosinophils, and neutrophils while the N/L ratio increases (Noda et al. 2007). N/L values are often used as a reference in determining chronic stress conditions in wild animals due to environmental influence (Davis et al. 2008). The mean value of N/L ratio in the seven blood samples was 0.53 which is lower than (Fair et al. 2006). N/L value is an accurate reference in determining the condition of chronic stress. However, this value is also influenced by the condition of infection that may occur in organisms. Even so, the stress condition is very closely related to the infection, which is stress increases an individual's susceptibility to infection while the condition of the infection can induce stress (Davis et al. 2008). Lymphocytosis and eosinopenia conditions experienced by bottlenose dolphins in this study can be caused by the adaptation process that occurs in dolphins in captivity.

Stress can be induced by environmental or dietary changes. Dolphins which lived in captivity as attraction animal could be stress because of somatic stressor form by loud noise generated during attractions (roar from the crowd, the sound of megaphones) and the treatment of transport; psychological stressor such as restraint and fights; behavior stressor form by too dense populations in pools; and other stressors such as malnutrition and the presence of infectious agents in animal bodies (Atkinson et al. 2015). In addition to observing various physiological parameters, observations of daily activity, feeding behavior, and behavior in groups must also be done in conducting stress assessment (Waples and Gales 2002).

The dolphin environment habitats in PT WSI Marine Mammals Conservation Site were six large pools with various depths. There were five pools in quarantine building and a pool in the show building. The depths of the pools at the quarantine building were between 3.5-6 m, while the depth of the pool on the show building was 2.5 $\mathrm{m}$. There were two to five dolphins on each pool. The depth of pool where dolphins lived should not less than the average dolphins body length that lived in the pool and one of the poolside should have depth not less than two times body length of bottlenose dolphins (SJVFS 2009: 92) which are 2.4-2.7 $\mathrm{m}$ (Jefferson et al. 2015). This means the depth of dolphin pools in PT WSI Marine Mammals Conservation Site already met the pool depth standard potentially reducing the level of stress experienced by the dolphins in human care.

The feeding management in PT WSI Marine Mammals Conservation Site was providing food which was fish every day as much as $3 \mathrm{~kg}$ and given three times a day in morning, noon, and evening. The food was the Upheneus sulphureus (Sulphur goatfish) and sometimes mackerel.
The nature dolphin's foods are fish and cephalopod that typically not longer than $30 \mathrm{~cm}$ (John and Yang 2009). Dolphins limit the choice of foods in the form of smallsized fish because dolphins do not chew their food but directly swallowed whole. Kuniran fish and mackerel have lengths not more than $30 \mathrm{~cm}$-This is accordant with natural food commonly eaten dolphin at sea so dolphins that were tested did not experience malnutrition caused by inappropriate food.

The health management in PT WSI Marine Mammals Conservation Site was quarantine for dolphins which had just come from a traveling circus. The medical examination of dolphins in PT WSI Marine Mammals Conservation Site done whenever the curator in charge reporting the indication of disease, such as decrease of appetite, there are wounds in dolphin's body, and indigestion. PT WSI Marine Mammals Conservation Site also did dolphin's blood check-up every 3 months regularly.

In conclusion, bottlenose dolphin from captivity in Kendal, Indonesia has slightly higher total erythrocytes and lower $\mathrm{MCV}, \mathrm{MCH}$, and $\mathrm{MCHC}$ values compared to freerange bottlenose dolphin. The $\mathrm{Hb}$ and $\mathrm{HCT}$ values are still in the range of values in the free-range bottlenose dolphin. The total value of leukocytes is lower than the free-range bottlenose dolphin. The relative values of neutrophils, basophils, and monocytes are still in the range of values in the free-range bottlenose dolphin. The relative value of eosinophil is smaller while the value of lymphocytes is greater than the relative leukocyte value in the free-range bottlenose dolphin. The N/L ratio is smaller than the freerange bottlenose dolphin.

\section{Conflict of interest}

All authors disclose that there are no financial, personal, or other associations that may influence or be perceived to influence the work.

\section{REFERENCES}

Aranda G, Lopez C, Fernandez-ruiz R, Esteban Y, Garcia-eguren G, Mora M, Halperin I, Casals G, Enseñat J, Hanzu FA. 2017. Circulatory immune cells in cushing syndrome : bystanders or active contributors to atherometabolic injury? a study of adhesion and activation of cell surface markers. Intl J Endocrinol 2017: 2912763. DOI: $0.1155 / 2017 / 2912763$.

Atkinson S, Crocker D, Houser D, Mashburn K. 2015. Stress physiology in marine mammals: how well do they fit the terrestrial model? J Compar Physiol B. DOI: 10.1007/s00360-015-0901-0

Bacha WJ, Bacha LM. 2000. Color Atlas of Veterinary Histology. Lippincott Williams \& Wilkins, Maryland.

Ciesla B. 2012. Hematology in Practice. F.A. Davis, Philadelphia

Corwin E. 2009. Buku Saku Patofisiologi. EGC, Jakarta. [Indonesian]

Davis AK, Maney DL, Maerz JC. 2008. The use of leukocyte profiles to measure stress in vertebrates: A review for ecologists. Funct Ecol 22: 760-772. DOI: 10.1111/j.1365-2435.2008.01467.x

Fair PA, Hulsey TC, Varela RA, Goldstein JD, Adams J, Zolman ES, Bossart GD. 2006. Hematology, serum chemistry, and cytology findings from apparently healthy Atlantic bottlenose dolphins (Tursiops truncatus) inhabiting the estuarine waters of Charleston, South Carolina. Aquatic Mammals 32 (2): 182-195. DOI: 10.1578/am.32.2.2006.182

Frandson RD, Wilke WL, Fails AD. 2003. Anatomy and Physiology of Farm Animals. 6th ed. Lippincott Williams \& Wilkins, Baltimore. 
Harvey JW, Stevens A, Lowe JS, Scott I. 2012. Veterinary Hematology. Elsevier Inc., Missouri.

Hickman DL. 2017. Evaluation of the neutrophil: lymphocyte ratio as an indicator of chronic distress in the laboratory mouse. Lab Animal 46 (7): 303-307. DOI: 10.1038/laban.1298

Ilardo MA, Moltke I, Korneliussen TS, Cheng J, Stern AJ, Racimo F, de Barros Damgaard P, Sikora M, Seguin-Orlando A, Rasmussen S, van den Munckhof ICL, ter Horst R, Joosten LAB, Netea MG, Salingkat S, Nielsen R, Willerslev E. 2018. Physiological and genetic adaptations to diving in sea nomads. Cell 173: 569-580. DOI 10.1016/j.cell.2018.03.054

Jefferson TA, Webber MA, Pitman RL. 2015. Marine Mammals of the World. Elsevier, Amsterdam.

John YW, Yang SC. 2009. Indo-pacific bottlenose dolphin: Tursiops aduncus. In: Perrin W, Wursig B, Thewissen J. (eds.), Encyclopedia of Marine Mammals. Elsevier Ltd., Amsterdam.

Lonsdale T. 1995. Periodontal disease and leucopenia. J Small Animal Pract 36 (12): 542-546. DOI: 10.1111/j.1748-5827.1995.tb02807.x

Noda K, Akiyoshi H, Aoki M, Shimada T, Ohashi F. 2007. Relationship between transportation stress and polymorphonuclear cell functions of bottlenose dolphins, Tursiops truncatus. J Vet Med Sci 69 (4): 379383. DOI: 10.1292/jvms.69.379

Nouri-Shirazi M, Bible BF, Zeng M, Tamjidi S, Bossart GD. 2017. Phenotyping and comparing the immune cell populations of freeranging Atlantic bottlenose dolphins (Tursiops truncatus) and dolphins under human care. BMC Vet Res 13: 1-14. DOI 10.1186/s12917-017-0998-3
Reidarson TH, McBain JF. 1999. Hematologic, biochemical, and endocrine effects of dexamethasone on bottlenose dolphins (Tursiops truncatus). J Zool Wildl Med 30 (2): 310-312. DOI: $10.2307 / 20095866$

Sarma PR. 1990. Red Cell Indices. In: Walker H, Hall W, Hurst J (eds.). Clinical Methods: The History, Physical, and Laboratory Examinations, Butterworths, Boston.

Shirai K, Sakai T. 1997. Haematological Findings. Aust Vet J 75: $317-$ 339. DOI: $10.1002 / 9780470751190 . \operatorname{ch} 27$

Stockham SL, Scott MA. 2008. Fundamentals of Veterinary Clinical Pathology. Blackwell Pub. Iowa.

Thomas A, Ono K. 2015. Diving related changes in the blood oxygen stores of rehabilitating harbor seal pups (Phoca vitulina). PLoS ONE 10 (6): 1-16. DOI: 10.1371/journal.pone.0128930

Thornton SJ, Spielman DM, Pelc NJ, Block WF, Crocker DE, Costa DP, LeBoeuf BJ, Hochachka PW. 2001. Effects of forced diving on the spleen and hepatic sinus in northern elephant seal pups. Proc Natl Acad Sci 98 (16): 9413-9418. DOI: 10.1073/pnas.151192098

Udroiu I. 2017. Storage of blood in the mammalian spleen: An evolutionary perspective. J Mammal Evol 24 (3): 243-260. DOI: 10.1007/s10914-016-9342-0

von Borell EH. 2001. The biology of stress and its application to livestock housing and transportation assessment. J Anim Sci 79: E260. DOI: 10.2527/jas2001.79e-supple260x

Waples KA, Gales NJ. 2002. Evaluating and minimising social stress in the care of captive bottlenose dolphins (Tursiops aduncus). Zool Biol 21: 5-26. DOI: 10.1002/zoo.10004 